\title{
REGIONAL BENEFITS IN FEDERAL PROJECT EVALUATIONS
}

\author{
Gunter Schramm ${ }^{1}$
}

\section{Introduction}

The purpose of this paper is to investigate to what extent, if any, regional income considerations should affect the selection, evaluation and scope of federal water resources projects. While the analysis is limited to this particular sector of federal activities, the findings should be readily applicable to other federal expenditure categories. The water resources sector was selected for two reasons: First, it has a longer and more concise history of exacting evaluation standards than any other federal expenditure activity, and, second, in recent months the U. S. Water Resources Council has developed a detailed new set of evaluation standards that deviate significantly from those applied until now. If these standards were to be adopted in the water resources field it is likely that they would be adopted for other federal expenditure categories as well, if only because of the undisputed leadership of the U. S. Federal Water Resource Sector in the area of the analysis of the benefits and costs of public investment activities.

What the U. S. Water Resources Council proposes is to set up a fouraccount system which would detail project effects in terms of (1) national income benefits and costs, (2) environmental quality, (3) social well-being, and (4) regional development objectives. ${ }^{2}$ These four objectives would be considered to be of equal rank so that trade-offs among them could be contemplated. Regional benefits would be accounted for by, "increases in a region's income, increases in employment, and improvement of the economic base, environment, social well-being and other specified components of the regional income objectives. " 3

The questions which we will try to ask and answer here are:

(a) Whether it is really appropriate for a federal agency to consider regional in addition to federal income objectives;

(b) Given an affirmative answer to (a), whether an agency should be permitted to trade off favourable regional against net national income gains;

(c) Given an affirmative answer to (a) and (b) whether the presently

${ }^{1}$ The author is Associate Professor of Resource Economics at the University of Michigan, Ann Arbor. The paper was financially supported by the Institute of Public Policy Studies and the School of Natural Resources of the University of Michigan.

${ }^{2}$ United States Water Resources Council, Standards for Planning Water and Land Resources, Washington, D. C. , July 1970, pp. 11-7, 11-19.

$$
3_{\text {Ibid. , p. 11-17. }}
$$


existing national efficiency requirement of benefits/cost $\geq$ is still a useful guide to project selection; and

(d) Whether the definition of a region is a useful concept even if we accept regional income effects as a legitimate goal for federal project evaluations.

As will be seen, the conclusions of this paper are quite sympathetic to the underlying objectives of the Water Resources Council proposals. However, significant doubts are raised about the efficacy of the proposed evaluation procedures. Alternative approaches are being suggested which hopefully will avoid some of the shortcomings of the proposed Water Resources Council procedures.

\section{The Water Resources Council Proposals}

The original 1969 proposals of the Water Resources Council have undergone several significant modifications in specific details but not in overall conception. Their key element is embedded in the proposal to create a fouraccount system which would analyze project objectives and effects under the four headings as outlined above.

While an analysis of the Environmental Quality and Social Well Being objectives are beyond the scope of this paper both of them are closely related to the Regional Development one. In particular, it will be shown below that the key-component of the Social Well-Being Account--which is income redistribution--really should be accounted for under the Regional Development objective (or vice versa).

Implementing the four-account system would have several important consequences. The first would be that more information would be made available to the public and ultimate decision makers. Under the separate account headings a much more detailed presentation of project consequences, both in terms of monetary and non-monetary benefits and costs, would become necessary. Hopefully, this information would also be presented in such a form that the major groups of people affected by the proposal could be identified. Such a detailed presentation would certainly be highly beneficial and help to improve the budget allocation and decision making process.

Much less clear, however, would be the effects of the four-account system on both the goal formulation and final project evaluation procedures. Instead of a single objective, namely national income maximization, ${ }^{4}$ there would now

${ }^{4}$ This statement is an obvious oversimplification. While national income maximization was generally the major planning goal of the operating agencies, numerous other objectives were generally incorporated into the analysis and ultimate project design. This was highly desirable from the planning agency's point of view which always had to be concerned about its local constituency and project supporters. It also had found explicit expression in the existing planning guidelines such as Senate Document No. 97 which declared that, "All view- 
be four major groups of objectives which, in almost all cases, would contain mutually exclusive elements. These conflicts would have to be resolved on the basis of some trade-off functions which no longer could be expressed in an unambiguous common denominator such as money. To solve this problem, several alternative strategies can be followed. Unfortunately, all have significant shortcomings. One would be to provide executive and congressional guidelines which would determine specific weights for each objective. Apart from the formidable task to devise a formula that would be acceptable for the various congressional and administrative interest groups, such a predetermined and uniform set of weights would be a rather inefficient device, given the diversity of water-related needs and resources existing in the various regions of the United States. A second alternative, which would impose fixed constraints on each objective, such as the imposition of environmental standards or, for example, the well-known condition that national efficiency benefit-cost ratios have to be equal or greater than one, again is likely to lead to substantial inefficiencies since no information would become available about the marginal trade-offs or costs of these constraints in terms of all other objectives. 5 The third alternative, and the one apparently favoured by the Water Resources Council, is to leave it up to the individual planning agency to assess the most appropriate weights in each individual case, and to "select a recommended plan from among the alternatives based upon an evaluation of the trade-offs among the various objectives. " 6 While the net national income costs of enhancing the non-national income objectives would be indicated in the proposed accounting framework it is clear that the planning agencies would have considerable discretion in the design, selection and scaling of individual project objectives. It is also clear that this would open the door widely for special interest pleading at the agency level and to potential account manipulations in response to such pressures. This very real danger is probably one of the major reasons why the President's Office of Management and Budget has refused so far to accept the Water Resources Council proposals in their present form. 7

While these are very real and important difficulties it is not possible to

points--national, regional, state and local--shall be fully considered and taken into account in planning resource use and development." See, the President's Water Resources Council, Policies, Standards, and Procedures in the Formulation, Evaluation and Review of Plans for Use and Development of Water and Related Land Resources, 87th Congress, 2d Session, May 29, $1962, \mathrm{p} .2$.

$5^{5}$ For a more detailed discussion of this point see Gunter Schramm and Robert E. Burt, Jr., An Analysis of Federal Water Resource Planning and Evaluation Procedures, The University of Michigan, School of Natural Resources, Ann Arbor, Michigan, June 1970. p. $\mathrm{V}-\mathrm{A}-3$.

${ }^{6}$ U. S. Water Resources Council, Standards---, op. cit. , July 1970,

${ }^{7}$ Conservation Foundation Newsletter, January 1971, p. 10. 
pursue them further within the context of this paper. Given the topic under consideration here, our discussion must be limited to the analysis of the appropriateness of regional income benefits and cost evaluations in federal project analysis. The discussion will concentrate on monetary regional income effects. This sidesteps the thorny issue of comparisons between monetary and non-monetary goals and objectives. In the real world, of course, these issues could not be disregarded as the proposed Water Resources Council guidelines themselves indicate. 8

\section{The Appropriateness of Regional Income Accounting}

Federal investments in water resources projects inevitably have a significant income redistributional effect. Project benefits are usually concentrated within a finite sub-national region. If they are non-reimbursable project beneficiaries enjoy the use of total project benefits without covering more than a small fraction of project costs. ${ }^{9}$ But even if they are reimbursable, the advantages of federal financing with its long pay-out periods, low interest rates and elimination of taxes bestow significant advantages on project beneficiaries.

There is little doubt that it would be useful to identify the net flow of resources within a region resulting from a proposed federal project. Given the significant impact of federal expenditures on specific areas such a regional impact accounting has become common practice for quite a number of federal agencies, most prominently among them the Department of Defense. 10

The more serious questions are whether federal projects should be specifically designed or redesigned for the purpose of influencing regional income flows, or whether the funding of authorized projects should be influenced

8 ${ }^{8}$ See also footnote (2).

$9_{\text {These costs would, at most, be limited to the fractional share of federal }}$ taxes that the beneficiaries contribute to the budget of the federal water resources construction agency. On an average per capita basis these tax contributions might be quite significant. For the ten-state southeastern region, for example, Haveman has estimated them to amount to approximately $41 \%$ of total benefits received (Robert Haveman, Water Resource Investment and the Public Interest, Vanderbilt University Press, Nashville, Tenn., 1965, Table 14). However, benefits are far from evenly distributed among the inhabitants of a region or state which means that some individuals would be net gainers and others net losers. Furthermore, it would be more sensible to assume that the elimination of any one federal water resources project would not lead to any decline in federal tax rates. Hence, the actual cost contributions of project beneficiaries would really be equal to zero.

10

See for example: "How Peace will Cut Employment," Business Week, Feb. 14, 1970. 
by regional income considerations. 11 Since many more projects are authorized than are funded in any given year ${ }^{12}$ such a selection pattern could have an important income redistributional effect.

Let us look at the possible rationale of the latter procedure first. It is obvious that such a policy would reduce total potential national income even if all authorized projects would be built eventually. Choosing a project with a lower benefit-cost ratio in preference to one with a higher one would necessarily produce lower near-future net additions to income for the nation as a whole. Since early net income streams have a higher present value than later ones total national income would be permanently reduced. Because of this aspect of apparent inefficiency many prominent economists such as Musgrave, for example, have argued against the inclusion of income distributional considerations into benefit-cost analysis. ${ }^{13}$ Instead, they recommend to deal with income distributional problems only through the tax-cash transfer mechanism.

However, it is not too difficult to show that this view represents a rather simplistic, and hence incorrect view of the world. There is little doubt that the marginal income utility functions of most individuals have a downward slope, even if almost all welfare economists will concede that the actual location and slope of these functions cannot be determined. By and large, however, there is general agreement among the members of our society that an additional dollar of income, on average, has a higher utility to a low income than to a high income person. From this it follows that a project I with a lower benefit-cost ratio might be as efficient in terms of total utility than a project II with a

${ }^{11}$ Such a procedure appears to be followed to some extent by Congress. As various observers have pointed out, the funding of authorized water resources projects follows no consistent pattern with respect to rankings by national efficiency criteria, although it appears to have an income redistributional bias towards lower income regions (See also R. Haveman, op. cit. Chpt. IV). Some analysts have gone so far as to conclude that this represents a deliberate congressional income redistributional policy. See Burton A. Weisbrod, "Income Redistribution Effects and Benefit-Cost Analysis," in Samuel B. Chase, ed., Problems in Public Expenditure Analysis, The Brookings Institution, Washington, 1968.

${ }^{12}$ In recent years, for example, average annual Army Corps of Engineers construction expenditures amounted to about 1.2 billion dollars while the ultimate federal costs of all authorized projects amounts to over 23 billion dollars, From: Conservation Foundation Newsletter, Jan. 1971, p. 2.

${ }^{13}$ See Richard A. Musgrave, "Cost-Benefit Analysis and the Theory of Public Finance," The Journal of Economic Literature, Vol. VII, No. 3, Sept. 1969 , pp. 803-805. While Musgrave acknowledges the possibility that income transfers in kind might be more desirable from the community's point of view, he still maintains that this solution is "second best in the absence of political constraints." (p. 804). 
higher one as long as the ratios of their respective per capita regional benefitcost ratios are equal to the inverse ratios of the respective average of the marginal income utilities of all project beneficiaries. ${ }^{14}$ Musgrave's prescription would be to build project $I$, to tax its beneficiaries and to redistribute income to individuals in project I area, since such a procedure would maximize total income and, after redistribution, also total utility. However, such a prescription is totally unrealistic, given our existing governmental and organizational structure. If project II were to be built, there would be no feasible way to tax its beneficiaries in favour of the potential beneficiaries of project I. Consequently, a project selection policy that would take account of and adjust for income distributional consequences may well be more rational and efficient in terms of overall welfare than one which concentrates only on national efficiency maximization.

However, this conclusion holds only if the income distributional consequences of the various alternative projects are known. As we will see below, it is not enough to ascertain that a particular project will have its main impact in a low-income region. What must be established, in addition, is that the project benefits realized within that region will actually go to low-income, rather than middle or high income groups. This important caveat will be discussed in greater detail below.

Let us now turn to the second issue, namely the question whether individual project designs should be changed in order to bring about net additions to regional benefits, even if such a redesign would result in a reduction of net national income benefits. According to the WRC proposals the answer to this question is an unqualified "yes," provided the regional income benefits appear to be desirable. ${ }^{15}$ For instance, in one of its illustrative examples the WRC details and recommends acceptance of a fictional project whose national income benefit-cost ratio would be equal to 0.77 , while its regional benefit-cost ratio, including secondary income benefits, would amount to 2.92 .16 If we accept the view--and at least the author of this paper would tend to do so--that income distributional effects towards lower income groups tend to increase total national welfare then no direct objections can be raised against such a trade-off between national and regional income objectives. However, what is needed

$$
\text { 14. E. }\left(\mathrm{B}^{\mathrm{I}} / \mathrm{C}^{\mathrm{I}}\right) \mathrm{U}^{\mathrm{I}}=\left(\mathrm{B}^{\Pi /} / \mathrm{C}^{\mathrm{II}}\right) \mathrm{U}^{\mathrm{II}} \text {, or }\left(\mathrm{B}^{\mathrm{I}} / \mathrm{C}^{\mathrm{I}}\right) /\left(\mathrm{B}^{\mathrm{II}} / \mathrm{C}^{\mathrm{II}}\right)=\mathrm{U}^{\mathrm{II}} / \mathrm{U}^{\mathrm{I}} \text { where }
$$
$\left(\mathrm{B}^{\mathrm{I}} / \mathrm{C}^{\mathrm{I}}\right)$ and $\left(\mathrm{B}^{\mathrm{II}} / \mathrm{C}^{\mathrm{II}}\right)$ are the respective regional benefit-cost ratios per capita for projects $\mathrm{I}$ and II and $\mathrm{U}^{\mathrm{I}}$ and $\mathrm{U}^{\mathrm{II}}$ represent the average of the marginal income utilities of project beneficiaries in the two project areas.

15 to VII-5-10.

U. S. Water Resources Council, Standards---, July 1970, pp. VII-4-1<smiles>[111InH]</smiles>
Ibid., pp. VII-4-1 to VII-4-5. 
again is a clear identification of the actual beneficiary groups by income classes so that it can be established that these regional benefits really accrue to lower income groups. Only if they do can a case be made for a trade-off between national and regional income objectives.

\section{The Rationale of a Minimum National Income Benefit-Cost Ratio}

Until now authorization of any project required that the national income benefit-cost ratio had to be at least equal to one. This well established rule makes little sense if we accept the view that other than national income objectives should be considered in federal project analysis. Let us demonstrate. In Figure (1) ABCDEFGHJK represents a fictitious project's trade-off function between net national and net regional income benefits. The latter are positive throughout while the former are first negative (below B), rise to a maximum (between $\mathrm{C}$ and $\mathrm{D}$ ), subsequently fall to zero (at $\mathrm{F}$ ), and then turn negative while regional net benefits still increase (up to J). Beyond $\mathrm{J}$ regional net benefits also decline. $I_{a}, I_{b}$, and $I_{c}$ represent various possible social welfare functions. $I_{a}$ represents the classical national efficiency approach while $I_{b}$ will result in the acceptance of some, and $\mathrm{I}_{\mathbf{c}}$ of very substantial trade-offs between net national and net regional income goals.

It is immediately apparent that the segments from $A$ to $D$ and from $J$ to $\mathrm{K}$ represent inferior alternatives in the classical Pareto sense since there are other solutions which result in a higher net benefit to at least one of the objectives without requiring a reduction in the net benefit to the other. If $I_{a}$ represents the decision maker's social welfare function he will be indifferent between points $C$ and $D$ (where the trade-off function has a horizontal slope). Presumably he will choose $\mathrm{D}$ over $\mathrm{C}$ since nothing must be sacrificed in terms of net national income gains while $D$ is superior to $C$ in terms of net regional income.

Let us now impose the usual restriction that the national income benefits must be at least equal to or greater than national income costs. This limits the trade-off function to the segment BCDEF. Now, if the decision maker's welfare function is represented by $I_{b}$ he will choose point $\mathbf{E}$ since at this point the constrained segment of the trade-off function is just tangent to his highest welfare indifference curve $I_{b}^{2}$. However, it can be seen that in the absence of the constraint he would in fact choose $\mathrm{I}_{b}^{3}$ which is tangent to the trade-off function at point $\mathrm{G}$ where net national income benefits are negative. Similarly, if the social welfare function has to be represented by $I_{c}$ the $B / C \geqslant 1$

constraint would force the selection of point $\mathrm{F}$ while in the unconstrained case point $\mathrm{H}$ would be much more desirable.

What we must conclude, therefore, is that the imposition of absolute constraints, such as minimum benefit-cost ratios, makes little sense if objectives other than national income maximization are to be included in the analysis.

The Concept and Limitations of a Regional Account

Major difficulties arise in defining the relevant region for the project analysis. The WRC recommends to establish some 173 so-called "economic 
FIGURE 1

Net National

Income Benefits \$

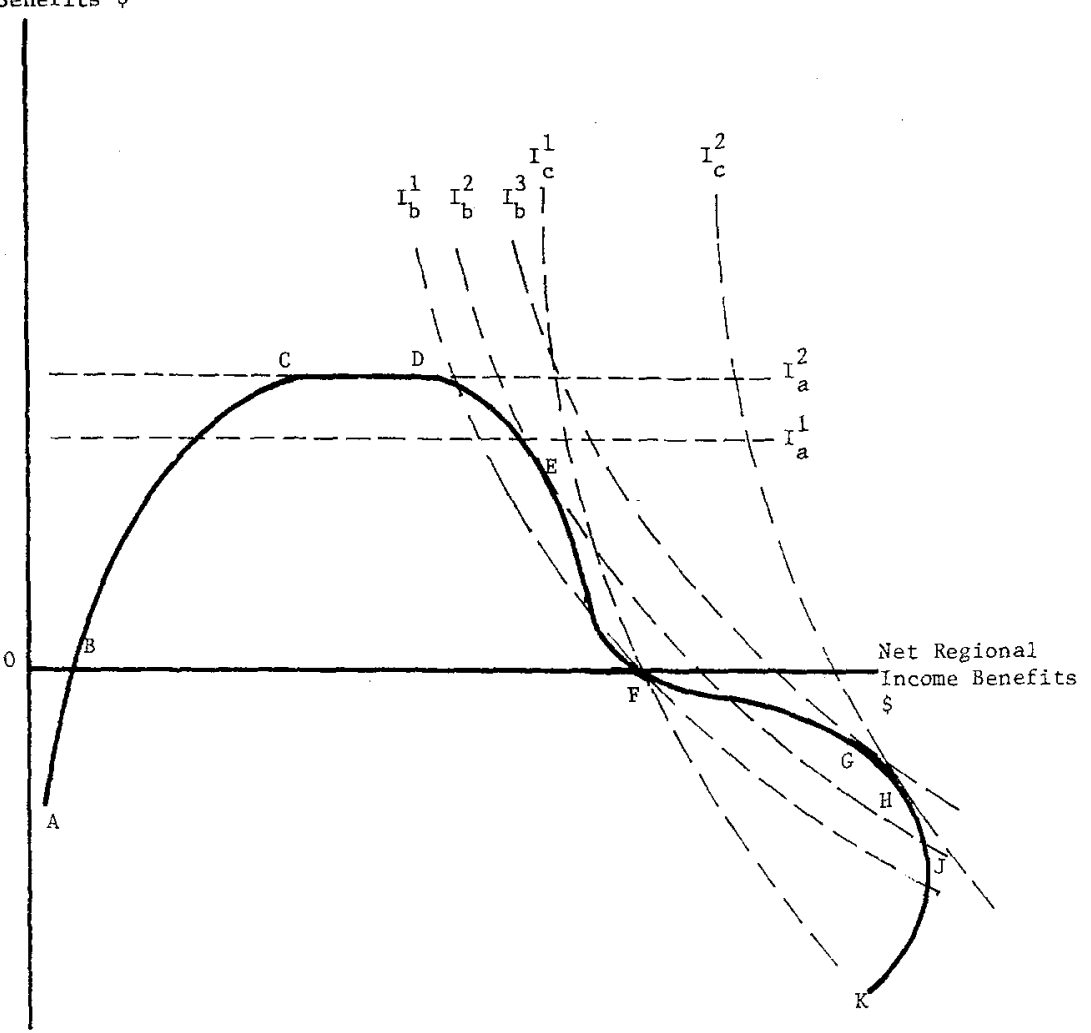

Net Vational

Income costs $\$$ 
accounting areas"17 and to analyze regional project effects within this pre-determined regional framework. As the Council states:

A plan may have effects on one or more of the economic accounting areas. As many economic accounting areas as necessary will be included in order to cover the geographic area relevant to the evaluation of the regional development objective. ----It is not proposed that the effects of a plan be identified across all of the individual accounting areas---. The evaluation will, however, as a minimum, analyze the effects of a plan upon the geographic area relevant to the evaluation of the regional development objective and the rest of the Nation. 18

Such a flexible accounting framework will serve a useful purpose in identifying major project impacts by geographic-economic sub-areas. It must be recognized, however, that most of the larger water resources projects will have impacts on widely differing areas. Irrigation, water supply and pollution abatement effects are likely to be tied closely to the local region in which the project is located. Large water storage and flood protection projects, on the other hand, may affect the water regime of the whole downstream reach of a river which could traverse quite a number of the proposed economic accounting areas. While these project benefits would at least occur within close geographic proximity to the water course, others, such as electric power or recreation may not. They may, instead, affect quite a different and often-times noncontiguous group of economic-geographic accounting regions. 19 The definition of the appropriate region will become even more complicated if the impacts of project costs and cost reimbursements are taken into account. In case of the latter, for example, tax-financed regional reimbursements are often paid out of state taxes so that the regional impact of a project may extend to all taxpayers of a given state. ${ }^{20} \mathrm{As}$ a consequence it is likely that any attempt to

17 These are identical to the OBERS economic projection areas developed by the Department of Commerce. p. VI-3.

${ }^{18}$ U. S. Water Resources Council, Standards---.. July 1970, op. cit. ,

19 For example, a survey of the potential impact of a major recreational development on the middle Susquehanna River in Pennsylvania found that the area was within four-hour driving distance of more than 25 million people. This would mean that a substantial portion of the non-priced recreational benefits from the Pennsylvania development would accrue to people living in New York, Newark, Baltimore, and other outside metropolitan areas.

${ }^{20}$ Given the cost-sharing formulas applying to recreational developments, for example, the above mentioned Susquehanna River recreation development would result in substantial net benefits to recreationists from New York State, New Jersey, Delaware and Maryland, while a substantial portion of the $50 \%$ reimbursement requirements would be paid out of State of Pennsylvania taxes. 
define the relevant region on the basis of the WRC proposals will result in a conglomerate of disparate economic accounting areas, many of which are tied together only on the basis of one but certainly not all project outputs or effects. On the other hand, the analysis might be limited to "the geographic area relevant to the evaluation of the regional development objective." 21 Such a procedure would almost invariably result in a strong bias towards the counting of favourable regional effects, while offsetting disadvantageous consequences occurring elsewhere would be disregarded. 22

The question which must be raised then, is whether these geographic reg ions could serve any useful purpose for the assessment of the merits of creating special regional net benefits that would require a net reduction in national benefits or a net increase in national costs. It is easy to see that the answer to this question must be negative. As we have seen above, net reductions in national income in favour of regional objectives can be justified only in terms of increases in total utility or total welfare. This means that all, or at least a large proportion of the additional regional benefits must go to lowincome or otherwise disadvantaged groups. Few, if any, water resource projects have much specific income-redistributional effects, For example, a new irrigation project in a low-income area may result in a significant expansion of economic activity and per capita income, but may not help the lowincome disadvantaged group residing in the area at all if the beneficiaries are newly established farmers that have been attracted from elsewhere. In such a case, the so-called regional net benefits represent no more than a direct transfer of economic activity from one area to another. Regional increases in economic activity, therefore, can be counted only as special regional benefits if they actually affect the economic fortunes of the specific disadvantaged groups living in the region. What is needed in addition to the regional accounting framework, therefore, is an analysis of the actual impact of project effects on specific people and groups of people. Only if these impacts can be established and measured is it possible to decide upon the real merits of proposed trade-offs between national and regional income objectives.

\section{The Impact Accounting System--An Alternative Proposal}

While the economic development of lagging regions has become a major policy objective for the Federal government in recent years ${ }^{23}$ it must be

${ }^{21}$ See also footnote $(18)$.

22 For example, the favourable regional construction employment effects of a hydropower project might be counted as a benefit, while the likely much greater deleterious effects on employment levels in depressed coal mining areas (which would have supplied thermal power plants in the absence of the hydro project) would more often than not be disregarded.

${ }^{23}$ See, for example, the Public Works and Economic Development Act of 1965 (Public Law 89-136) and the Appalachian Regional Development Act of 1965. 
recognized that the underlying objective of regional development is less concerned with the fortunes or misfortunes of a region as such than with the fortunes or misfortunes of the people living within it. Hence, regional development goals are primarily development goals for people, not for regions. To the extent that federal water resources projects will further such regional development goals they can do it only by improving directly or indirectly the economic well-being of the disadvantaged groups living within these regions. What is needed, therefore, is an analysis of the total net economic impact of such projects on these groups, rather than an accounting framework which identifies no more than the aggregate regional economic effects. 24

Several steps are needed to provide the necessary information. The first is the drawing up of a national income maximization plan which excludes any special allowance for other objectives. Such a plan is needed even if it is quite certain from the outset that other goals, such as regional income enhancement, will be of major importance for the final plan selection. The unconstrained national income maximization plan is needed to measure the costs of the other objectives in terms of foregone national income net benefits. 25 In this way a shadow price can be established for them.

The second step is the analysis of future developments in the "without" case. This analysis is important for several reasons. The first and most obvious one is that it will prevent the inclusion of the net benefits of developments that will take place in the absence of the project as part of project

${ }^{24}$ Construction expenditures provide a typical example. Legislators-particularly at election time--are fond to quote the total dollar costs of water resources projects which are being built within their election district. However, as Haveman and Krutilla as well as others have shown, only some 15-40\% of total construction expenditures really represent local expenditures. The balance goes to outside suppliers. Of local expenditures, most go to construction labor. But construction labor is highly specialized, highly unionized and highly mobile. Most of the construction site labor requirements will be filled by construction workers from outside the region. If the region is permanently economically depressed it is unlikely to contain many members of the required skilled construction trades. At best, therefore, the region itself will supply the unskilled labor force, whose wages generally do not account for more than $3-7 \%$ of total construction expenditures. If we accept Haveman's and Krutilla's view that even at high unemployment rates the likelihood of drawing from the unemployed labor pool is less than $100 \%$ then it can be seen that the direct local employment effect of a construction project might be very small indeed. Data from: Robert H. Haveman and John V. Krutilla, Unemployment, Idle Capacity and the Evaluation of Public Expenditures, Johns Hopkins, Baltimore, 1968, Table 6 .

${ }^{25}$ The total costs consist of the sum of the separable costs and the net reduction in national income benefits attributable to the introduction of the non-national income objective. 
benefits. The second reason is a managerial one. Our water resources agencies no longer are (or at least should be) simply project oriented construction agencies, but rather management agencies with a comprehensive responsibility for the most beneficial management of our water resources. The decision not to build a project at a particular site, therefore, is as important a management decision as to build one, and it will result in a flow of social benefits and costs that must be carefully accounted for. The third reason for the detailed analysis of the "without" case is most directly related to the proposed impact accounting system. By tracing the flows and impacts of the benefits and costs occurring in the without case it will be possible to assess the net differential of these benefits and costs as they occur to the respective groups affected by them. In other words, the detailing of the "without" case consequences allow the measurement of the opportunities foregone.

In order to measure the likely incidence of project effects both the cost and benefit flows of the income maximization plan and the "without" analysis must be traced and presented in as much detail as possible. In many cases, and particularly in those in which trade-offs between national and regional objectives are contemplated, special information, such as unemployment rates and incidence, employment categories and others would have to be provided.

Once all the information that appears to be relevant has been collected and presented alternative plans which include specific regional development goals can be drawn up. These plans have to provide the same impact information as the unconstrained national development plan. Such a presentation will allow a ready comparison of all project effects. It will permit a detailed analysis of the national efficiency losses resulting from the inclusion of regional development goals, and it will permit the tracing of the incidence of project benefits and costs. Only, and only if this information is provided in sufficient detail can a rational decision be made whether specific regional objectives merit a trade-off in terms of national efficiency losses. Without this information, the so-called merits of regional development goals would simply become another grab-bag for federal funds that serve no other purpose than to enrich some influential regional interest groups. 